\title{
COMPARATIVE FIELD CAGE TESTS OF THE POPULATION SUPPRESSING EFFICIENCY OF THREE GENETIC CONTROL SYSTEMS FOR AEDES AEGYPTI
}

\author{
C. F. CURTIS,*† K. K. GROVER*, S. G. SUGUNA*, D. K. UPPAL,* K. DIETZ‡, \\ H. V. AGARWAL* and S. J. KAZMI* \\ WHO/ICMR Research Unit on Genetic Control on Mosquitos, New Delhi, India
}

Received 6.vi.75

\begin{abstract}
SUMMARY
Cycling populations of Aedes aegypti were set up in cages and managed in such a way that the populations had a maximum of threefold recovery potential in response to control measures. Into three such populations daily releases were made of males which had been chemosterilised, or were double translocation heterozygotes (TIT3) or TIT3 with sex ratio distortion (DTIT3). Eradication of the populations was achieved with all cases, but the rate of suppression was markedly slower with TIT3 than the other two systems, with which the rates were similar. T1T3 and DTIT3 releases introduced considerable inherited genetic loads into the target populations. The results were in general agreement with computer predictions.
\end{abstract}

\section{INTRODUCTION}

Aedes aegypti is an important vector of arbo-viruses and considerable attention has been given to the possibility of its control by genetic means (Craig and Hickey, 1967).

Among the genetic systems available, chemosterilisation by means of thiotepa treatment at the pupal stage was reported by White (1966). The use of this chemical as a pupal sterilant has been further studied, and techniques for mass sterilisation have been developed (Grover and Sharma, 1974; Grover and Agarwal, 1975).

Viable translocation homozygotes have been produced (Lorimer, Hallinan and Rai, 1972; Rai, Lorimer and Hallinan, 1974) which makes possible the mass production of double translocation heterozygotes by crossing different homozygous strains (Curtis and Robinson, 1971; McDonald and Rai, 1971). Studies have been made (Uppal, Gurtis and Rai, 1974) on a double heterozygote (T1T3) produced by crossing two homozygous I:III translocations (T1Tl and T3T3).

A meiotic drive factor causing distortion of the sex ratio in favour of males has been reported (Hickey and Graig, 1966 a and $b$; Hickey 1970). Distortion only occurs in the progeny of males carrying both a factor $M^{D}$ at or very close to the male determining $(M)$ gene, and also a factor $m^{d}$ at or close to the female determining $(m)$ gene. The other male genotypes $\left(M^{D} m^{D}, M^{d} m^{d}\right.$ and $M^{d} m^{D}$ ) show normal sex ratios. The $M^{D}$ factor has been linked to the Tl homozygous translocation (Suguna and Curtis, 1974, Suguna et al., 1975). Computer simulation suggested that integration of translocation partial

* WHO/ICMR Research Unit on Genetic Control of Mosquitos.

$\dagger$ Present address: VBC, WHO Headquarters, Geneva, Switzerland.

$\ddagger$ Health Statistical Methodology, WHO Headquarters, Geneva, Switzerland. 
sterility and sex ratio distortion is a promising technique for genetic control (Curtis et al., 1975) and males with double translocation heterozygosity and sex ratio distortion (DT1T3) have been produced (Suguna and Curtis, 1974) as shown in fig. 1 .

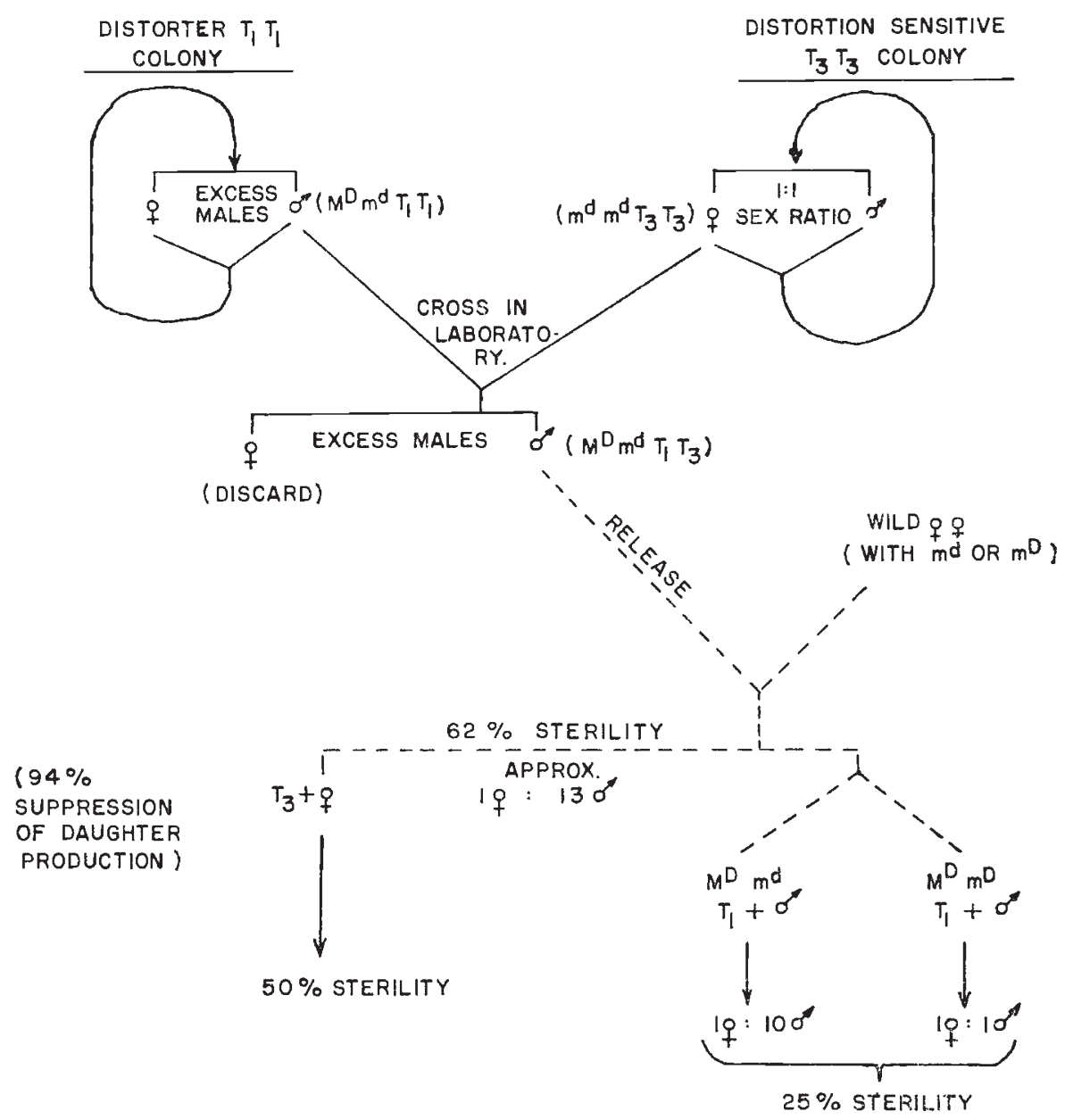

FIG. 1.-Method of production and properties of DT1T3 males. $M^{D}, m^{d}$ and $m^{D}$ are the distorter, distortion sensitive and distortion resistant genes (Hickey and Craig, 1966b) and $\mathrm{T} 1$ and $\mathrm{T} 3$ and I:III translocations viable in the homozygous state.

One of the factors to be considered in choosing which of these three systems to use in large field experiments on genetic control is the relative efficiency of the systems for population suppression, i.e. the relative numbers that would have to be released to achieve a given level of suppression of a population. Wild populations, which were isolated, comparable in their natural seasonal trend and small enough for three simultaneous experiments to be logistically feasible, were not available. Preliminary tests have been carried out (Curtis et al., 1975) of the effects of releasing translocated or distorter males into cycling populations of $A$. aegypti maintained in large 
outdoor cages (field cages), and it was considered that the field cage systems could provide meaningful comparisons of different genetic control systems, if used in conjunction with studies of mating competitiveness in the field.

The population recovery potential (i.e. strength of density dependent regulation) is of great importance in determining the ability of a genetic system to suppress a population. Conclusive field data on this parameter are not yet available, but there is evidence ( $R$. Reuben, personal communication) for the existence of density dependence of survival of $A$. aegypti larvae in urban domestic breeding situations. It is also known that in some breeding sites larval mortality is due to human activities, which are presumably independent of mosquito larval density. Thus a moderate population recovery potential seems to be applicable, and for this experiment a system giving a maximum of three-fold recovery potential per generation was adopted. It was originally intended to arrange the rearing system so that there was sufficient competition for larval survival to give the desired density dependence relationship. However, it was found that this system produced very small adults which could not survive under the ambient hot weather conditions. Therefore, an indoor larval rearing system at a non-competitive density was adopted and the number of pupae to be returned to the field cages was calculated from a chart of the chosen density dependence relationship (see inset to fig. 4) and the remainder of the pupae were destroyed.

The total number of eggs laid by a population is expected to decline proportionately as the adult population is suppressed. However, there was reason to doubt whether this proportionality applied equally in the different field cages in which the experiment was to be conducted. Therefore, a constant relationship was assumed between number of female pupae returned to the cage population on a given day and the number of eggs expected to be laid an appropriate number of days later, and this assumption was built into the population management system as detailed in the Methods section.

Computer simulations of the three systems were carried out to gain insight into their behaviour when released into populations and to determine what release schedules would give the most informative comparison between the systems. The simulations indicated that inherited genetic load would make an important contribution with DTlT3 and T1T3 release programmes and that the effects of terminating releases at various times should be studied in the caged populations to determine whether, and at what stage, sufficient inherited load could be built into the populations to ensure their eradication or prolonged suppression.

\section{Materials AND MEthods}

\section{(i) Management of the populations}

The field cage and provision of food for the adult mosquitos were as described by Curtis et al. (1975). In each cage eight black jar ovitraps (Fay and Elliason, 1966) were set and these were equipped with five strips of orange brown cloth (Reuben et al., 1975). The cloth strips were collected daily, the eggs were conditioned (Fay, 1964) for 4 days and placed for 2 days in water after which the hatchability was counted. From the hatched eggs from each cage on each day, two sets of 100 larvae were cultured in bowls containing $500 \mathrm{ml}$ of water. They were held at $28 \pm 2^{\circ} \mathrm{C}$ and fed on a mixture 
C. F. CURTIS $E T A L$.

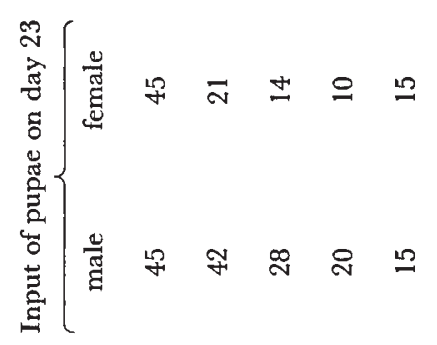

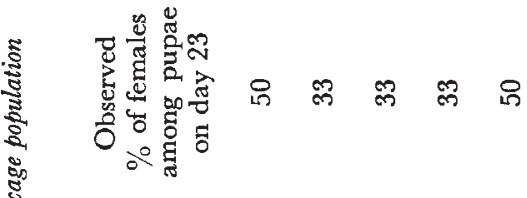

๘

ฐิ

๕ัँ

हूँ

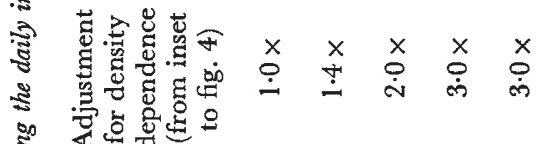

변

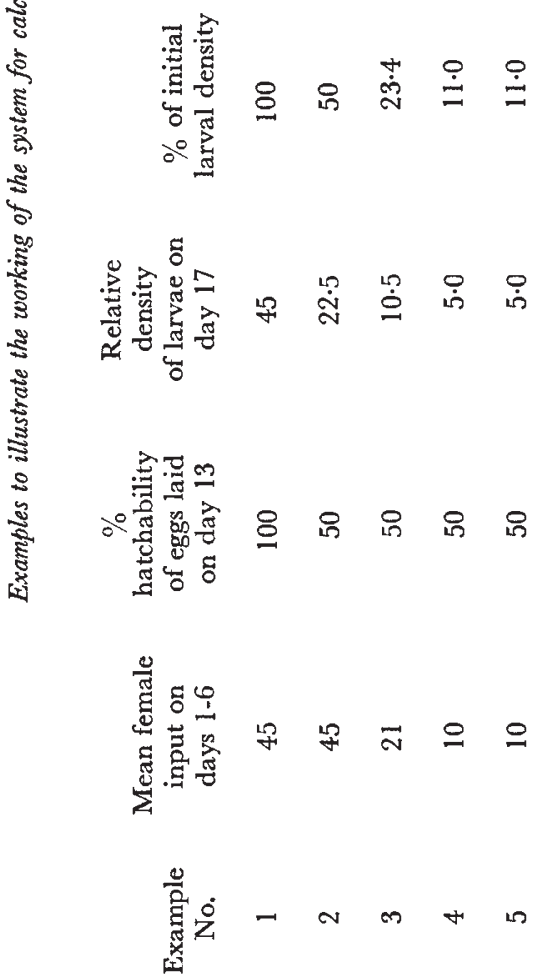


of 60 per cent powdered dog biscuit and 40 per cent yeast. The water was changed every third day.

Pupae were collected, sexed by their size and the males and females allotted for return to the cage population were placed in separate containers for emergence. The sexing was checked on the first day of adult life and the mosquitos were then released into the cage from which they had originated.

Before the releases of sterile or translocated males began, 45 male and 45 female pupae were re-cycled each day into each of the cage populations. It was required that when genetic control was applied the number of adults returning to the cage populations should depend on the following factors: the number of egg-laying females in the previous generation, the hatchability of their eggs, the assumed density dependence relationship of larval survival, and the current sex ratio among the pupae. To achieve this, the following calculation procedure (based on the observed durations of the life cycle stages) was used each day. The mean number of female pupae allowed to emerge into the cage population on days 1-6 was multiplied by the hatchability of eggs laid on day 13 to give a measure of the expected number of hatching larvae on day 17 . This was then adjusted by the density dependence relationship shown in the inset of fig. 4, and multiplied by two to obtain the number of pupae of both sexes to be allotted on day 23 for return to the cage population. In the case of the releases of chemosterilised and TIT3 males a 1:1 sex ratio was used among the pupae, but in the case of DT1T3 the sex ratio of the pupae was made proportional to the observed sex ratio in the rearing bowls on day 23 .

The working of the calculation system is illustrated by five examples in table $\mathrm{l}$ in which different densities and genetic loads lead to population decrease, constancy or increase.

\section{(ii) Mosquito stocks}

The initial "target" populations, and also the males for chemosterilisation, were obtained from a mass-reared colony of $A$. aegypti which originated from the town of Sonepat (Haryana State, India). The methods of rearing, separation of larvae and pupae, and sexing the pupae were those described by Singh, Brooks and Ansari (1974). For chemosterilisation the pupae were dipped for 3 hours in a 0.6 per cent solution of thiotepa (buffered at $p \mathrm{H} 7.5$ ) and subsequently rinsed twice in clean water before being caged for emergence. (Grover and Sharma, 1974; Grover and Agarwal, 1975).

The TIT3 and DTIT3 material was reared on the same diet as used in the mass rearing colony, but the rearing was conducted on a smaller scale (approx. 300 larvae in one litre of water). The pupae were individually sexed on the basis of their size.

The T1Tl translocation homozygote was produced by Lorimer et al. (1972). Genetic background of Indian origin was introduced into TlT1, and the T3T3 homozygote was produced in an Indian stock as described by Rai et al. (1974). TIT3 double heterozygotes were produced by crossing T1T1 homozygous males to T3T3 homozygous females.

The purity of the homozygous stocks was checked by outcrosses to a marker stock followed by tests for pseudo-linkage of markers.

DT1T3 males were produced as illustrated in fig. 1. The T3T3 maternal stocks were derived from single pairs and were checked for their homozygosity 
for the distortion sensitive $\left(m^{d}\right)$ gene by crossing samples of T3T3 females to distorter males and checking that all the male progeny gave sex ratio distortion when they were mated. Further details of the DTIT1 (paternal) stock are given by Suguna et al. (1975).

\section{(iii) Release programme and procedure}

Four cycling populations of wild type $A$. aegypti were established at the beginning of May 1974 (i.e. in the hot dry season). One population was allowed to cycle undisturbed as a control and, into the others, daily release of males of the three different types began on 19th May. The DTIT3 release programme had to be stopped due to contamination of the maternal T3T3 stock and it was re-started with purified material; the wild type "target" population for this was initiated on 1st August (i.e. in the monsoon) and the DT1T3 releases started on 6th September (i.e. in the post-monsoon season). In the last stages of the DT1T3 releases (on 12th November) the population was brought indoors into $60 \mathrm{~cm}$ cube cages because the onset of winter temperatures would have prevented reliable egg laying in the field cage.

The daily release rate was, in each case, 450 males per day, i.e. 10 times the initial daily rate of male emergence in the target population. The batches of 450 pupae were placed in water in cylindrical plastic cages $(13 \mathrm{~cm} \times 1 \mathrm{~cm}$ diameter) for emergence, the water was drained after the completion of emergence. Any females not removed at the pupal stage were removed after emergence. The adults were then marked with fluorescent powder (" neon red" in colour) by blowing a mist of the powder through the netting top of the cage (Singh et al., 1975) using an air pressure of $40 \mathrm{lb} / \mathrm{sq}$ in. Five hours after marking, the mosquitos were released into the field cages: at the time of release they were 36-60 hours old. A sample of about 100 adults were captured with a sweep net from each cage weekly and classified, under the microscope after etherisation, as marked or unmarked. After recovery, these mosquitos were returned to their respective cages.

\section{(iv) Computer simulation}

The computer model was basically that described by Curtis et al. (1975). The model simulates an isolated population with overlapping generations and with density dependence of larval survival. The mean lengths of male and female adult life span were set to conform with the available data for field cage conditions ( $R$. Reuben, personal communication) and the strength of density dependent regulation was such as to give a maximum of three-fold population recovery potential. The model is deterministic and assumes perfect mixing of the released and wild mosquitos.

There are three sub-routines available for simulating the genetic consequences of matings between different sets of genotypes; the two described by Gurtis et al. (1975) simulate (a) all 100 possible matings involving two nonsex linked translocations which can recombine with each other, and (b) all 160 possible matings involving a sex linked translocation and a sex ratio distorter system (including the distorter and non-distorter $M$ genes $\left(M^{D}\right.$ and $\left.M^{d}\right)$ and the distortion resistant and sensitive $m$ genes $\left(m^{D}\right.$ and $\left.\left.m^{d}\right)\right)$. The third sub-routine (c) has been added to simulate sterilised males where there is no inheritance of sterility. The fertility, mating competitiveness and 
extent of sex ratio distortion of the genotypes can be specified for each simulation.

Sub-routine (a) was used in the present study to simulate the release of T1T3 double heterozygotes produced by the two reciprocal crosses of T1T1 and T3T3 homozygotes. Though both translocations are in fact sex-linked, it is considered that the releases of equal numbers of the $M$ and $m$ linked version of each translocation would be equivalent to the use of autosomal translocations.

For simulation of the release of T1T3 or DT1T3 bred from the cross of T3T3 females $\times$ T1T1 or DT1T1 males, the sex linkage of the translocation cannot be ignored and sub-routine (b) was used, the male double heterozygotes being represented by the genotype originally intended to represent distorter male translocation homozygotes. This accurately simulates the the outcome of the first generation of mating by the double heterozygotes with wild type (all progeny are single heterozygotes), but it makes no provision for the production of male translocation homozygotes or female double heterozygotes which could ultimately occur as a result of recombination in single heterozygotes.

Data reported in the Results section of unpublished data of Reuben, Suguna, Uppal and Grover were used in the simulations as follows:

\section{Fertility:}

chemosterilised males, 0.4 per cent; T1T3, 27 per cent; DT1T3, 38 per cent; $\mathrm{DT} 1+, 75$ per cent; $\mathrm{T} 1+$ and $\mathrm{T} 3+, 50$ per cent; $\mathrm{TlT} 1,70$ per cent; T3T3, 90 per cent; cross-matings between translocated genotypes are assumed to have fertilities which are the products of the fertilities of each parent mated to wild type, though this is only an approximation to the true situation.

Sex ratio:

DT1T3, 7.5 per cent females (fig. 1); distorter without translocation, 15 per cent females; T1T3 was simulated with sub-routine (b) but with no distortion. The frequency of the $m^{D}$ (distortion resistant) allele in the initial population was set at 30 per cent.

Crossing over between translocation and sex locus:

$\mathrm{T} 1 \mathrm{~T} 3$, zero; $\mathrm{DT}_{1}+, 22$ per cent.

Mating competitiveness:

assumed 100 per cent in all cases.

Females released:

Zero in all cases, to conform with the conditions used in the cage experiments.

Daily loss rates :

Males: 43.9 per cent; females: 16.9 per cent.

\section{Results}

\section{(i) The computer simulations}

Various release schedules were tested and its was found that 60 daily releases of a number of chemosterilised males equal to 10 times the initial daily emergence rate of males should be sufficient to reduce a population of 
the size used in the cage experiment to less than one of each sex per generation, i.e. to eradication. However, the model predicted recovery of any residual population under the influence of the assumed three-fold recovery capacity when the sterility pressure of continued releases was removed (fig. 2). This emphasised that release of chemosterilised males should continue up to the point of eradication if fairly rapid regeneration was to be avoided.

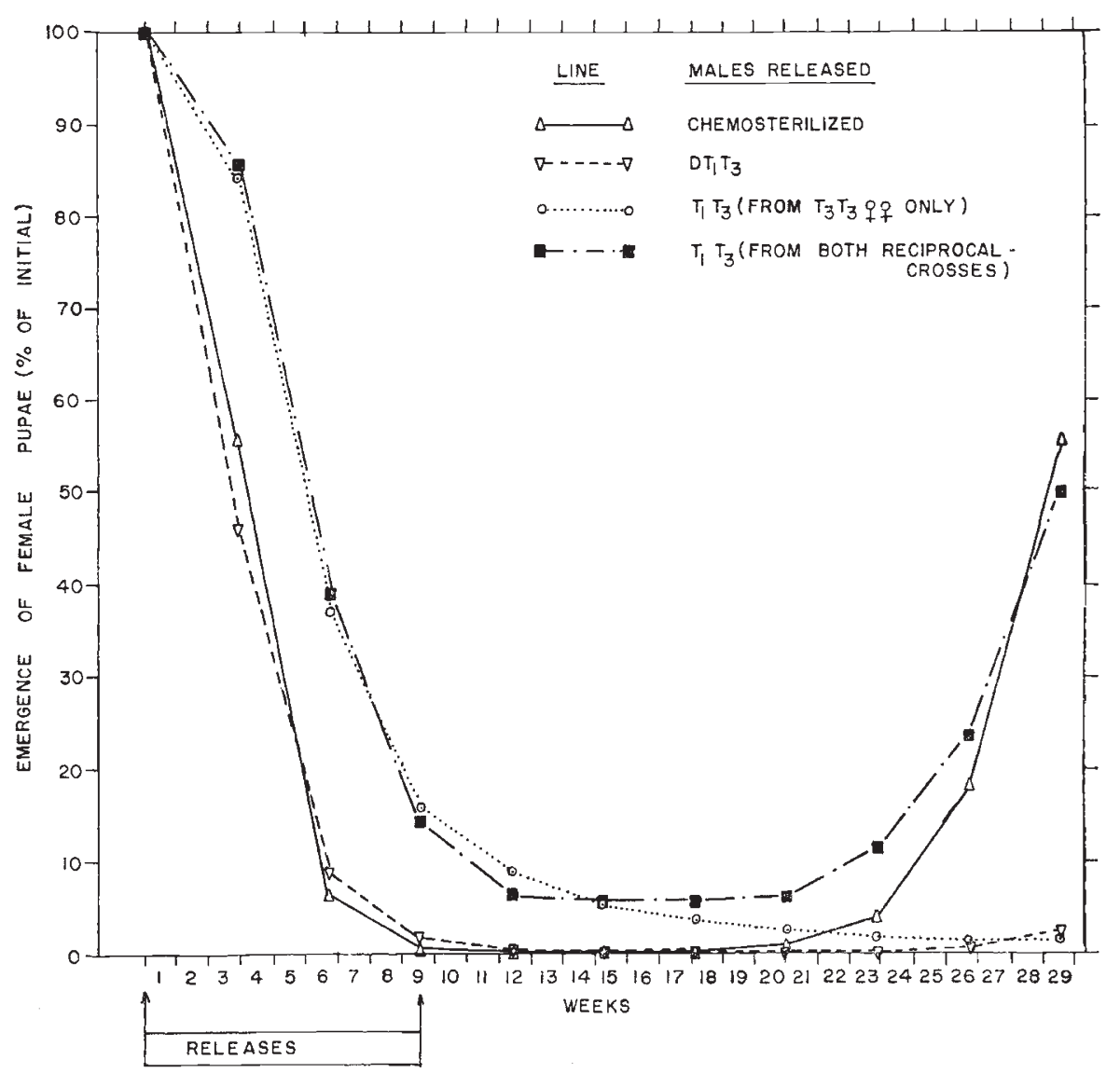

FiG. 2.-Results of computer simulations of the effects of release of males of the four types specified. The data and assumptions used are specified in the text.

Release of T1T3 derived from T3T3 females $\times$ T1T 1 males gave relatively slow population suppression (fig. 2). The female population came to consist largely of T3T3 homozygotes. Among males, T1T3 rose to a peak and then declined, to be surpassed by $M+/ m \mathrm{~T} 3$ single heterozygotes in week 29 . Crossing over can occur in $M+/ m$ T3 males to cause T3 to become $M$ linked and hence the production of fully fertile T3T3 males, and the regeneration of the residual population, is expected eventually to occur.

Where both reciprocal crosses were used to produce T1T3, both $M$ and $m$ linked versions of the T3 translocation were released. Numerous T3T3 males and females with nearly full fertility were therefore produced and favoured 
by selection. Satisfactory control of the population was therefore not achieved (fig. 2) and this system was not tested in the cage experiments.

The simulation with DT1T3 (fig. 2) showed a similar rate of population suppression as with chemosterilised males, and after termination of releases, control of any residual population was maintained for about 20 weeks, as a result of inherited partial sterility and sex ratio distortion. However, eventually selective elimination of the $\mathrm{Tl}$ translocation and selective increase in the frequency of $m^{D}$ reduced the genetic load and allowed recovery.

\section{(ii) Cage experiments}

\section{(a) Comparison cage}

In the comparison cage, which was allowed to cycle without release of any sterile or translocated males, the egg hatch remained close to 100 per cent and the sex ratio close to 50 per cent female throughout (fig. 3) and in this cage the initial level of pupal input ( 45 males and 45 females per day) was continued until the end.

\section{(b) Chemosterilised male releases}

Daily checks on the chemosterilised males mated to untreated females showed a mean of 99.68 per cent sterility (range between daily means: 98.0-100 per cent, from daily samples of 800-3500 eggs).

In the cage with chemosterilised male releases, at a rate of 450 per day, egg hatchability declined to less than 10 per cent within 4 weeks of starting releases (fig. 3). There were then two higher peaks of fertility in weeks 8 and 10 , but finally the hatch declined to zero in week 12, after which egg laying ceased. The population, as measured by the input of pupae, calculated as described above, was suppressed rapidly and reached eradication (no pupal input for 14 days) (fig. 4). The last input of pupae was at day 77 and chemosterilised releases were terminated 5 days later, i.e. in week 12.

The observed marked:unmarked ratio among males captured in the cage, related to the ratios of numbers of chemosterilised males released to numbers of males recycled into the cage population are shown in table 2 . There was generally a fair correspondence between these expected ratios and the observed ratios in the following week, indicating approximately normal survival of the marked, chemosterilised males.

\section{(c) T1T3 male releases}

All the T1T3 release material was derived from two mass crosses of T3T3 females $\times$ TlTl males. Eggs were conditioned, dried, "banked" and samples were then hatched and test-mated to wild type before use of the material for releases. Tests of 55 individual males from the first batch gave a mean egg hatch of 29.0 per cent (range $4-40$ per cent) and 20 males from the second batch gave 24.5 per cent hatch (range 12-39 per cent). A mass test cross of this material gave $25 \cdot 8$ per cent hatch.

Releases of T1T3 males in the field cage caused a relatively slow decline in egg hatchability (fig. 3), but with continued releases the hatch eventually declined to less than 20 per cent, i.e. considerably less than that of matings of TIT3 males to wild type. This indicated a considerable contribution to sterility from translocations released at earlier generations and inherited by females of the cage population. Thus the sterility was sufficient to overcome 


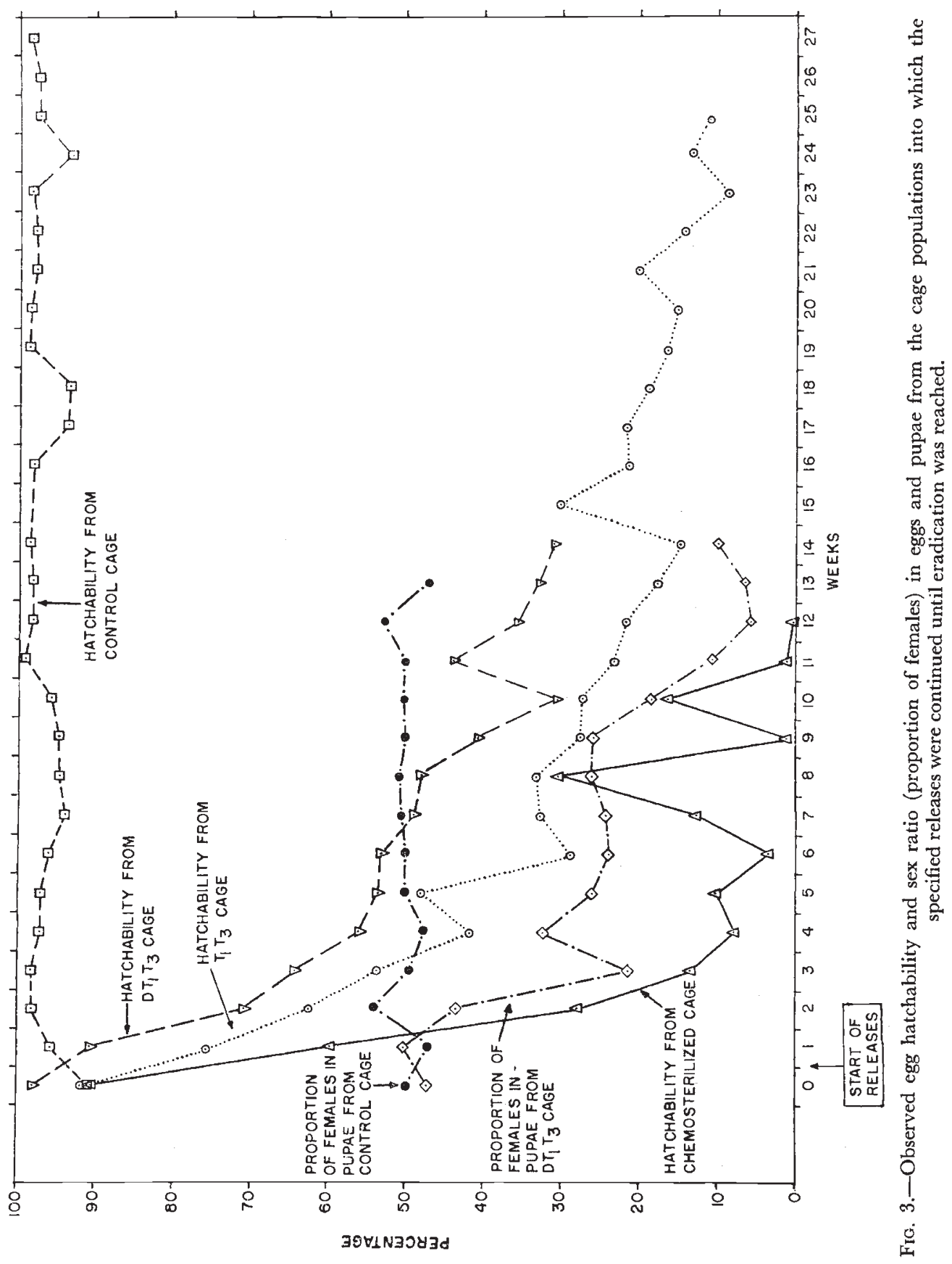




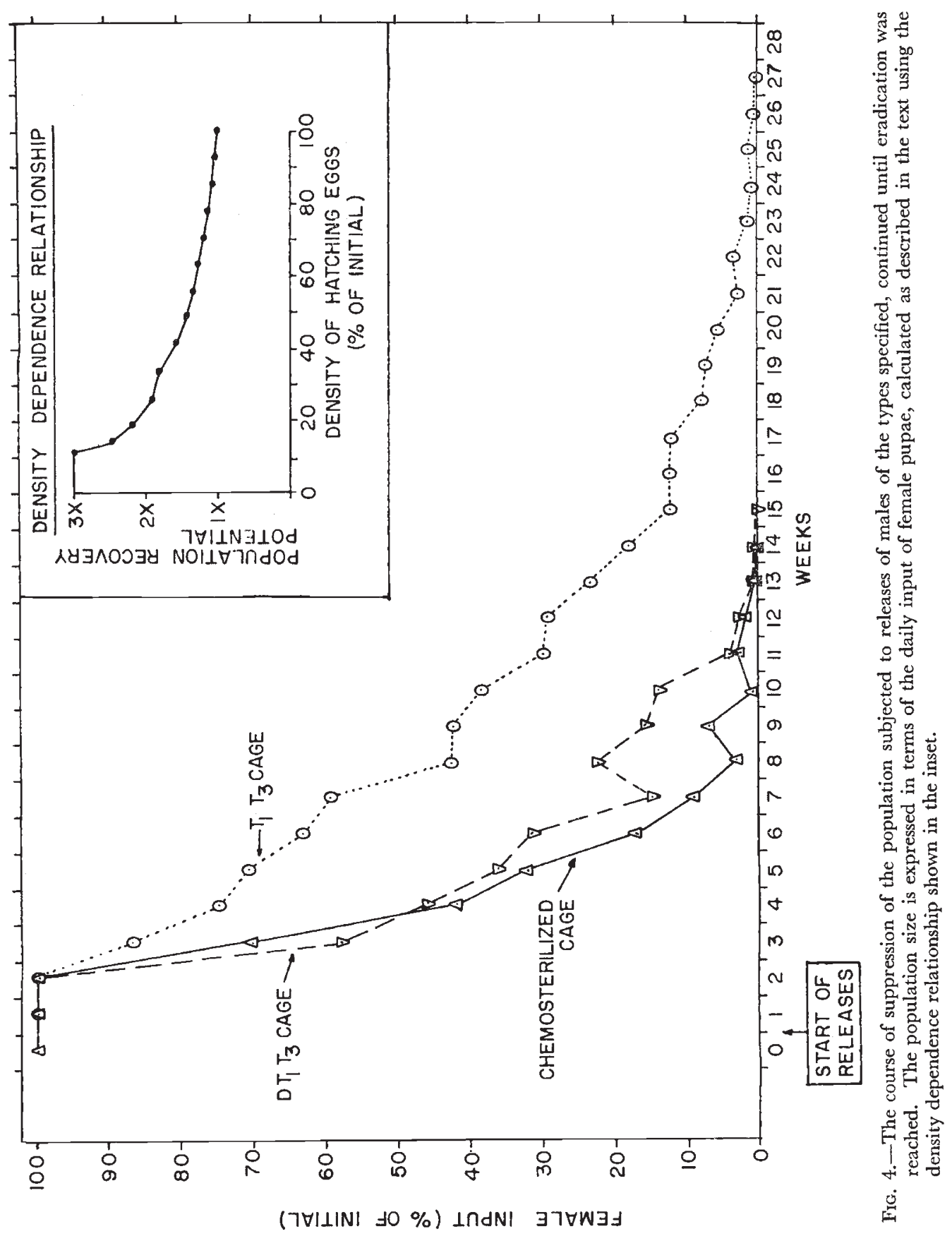


TABLE 2

Relationship of observed marked: unmarked male ratios to the ratios of (number of released chemosterilised or translocated males): (number of emerging pupae returned to the cage population)

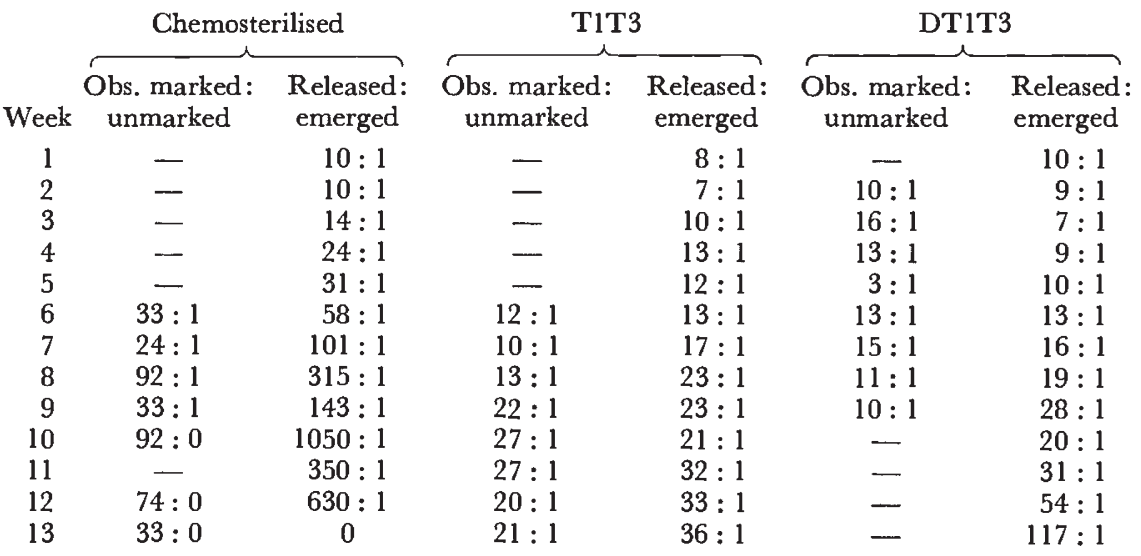

Notes: (i) 3150 chemosterilised and DT1T3 males released each week until termination of release in weeks 12 and 13 respectively. An average of 2792 T1T3 males was released in weeks 1-13 and subsequently the number released was allowed to decline gradually to 700 in week 23 after which releases were terminated. (ii) The marked : unmarked ratios were based on samples of about 100 caught each week.

the maximum recovery potential applied to the population $(3 x)$ and there was a slow but continuing downward trend in population to eradication (i.e. no pupal input) in week 27 (fig. 4).

The ratios of marked:unmarked males increased approximately as expected from the release ratio (table 2) indicating normal survival of T1T3 males.

Samples of pupae from the population not required for the calculated inputs into the cages were allowed to emerge and test mated to wild type to identify their genotypes. The results are shown in table 3 . Prior tests had shown that, with a very few exceptions, males or females could be identified by their fertility as follows: below 40 per cent hatch, T1T3; 41-70 per cent, single heterozygotes $(\mathrm{T} 1+$ or $\mathrm{T} 3+)$, above 70 per cent homozygotes. The progeny of the latter were reared and test mated to distinguish T3T3 homozygotes, which gave semi-sterile progeny, and wild types which gave fully

TABLE 3

Genotype frequencies among pupae from the population exposed to T1T3 releases.

\begin{tabular}{|c|c|c|c|c|c|c|c|c|c|c|}
\hline \multirow{3}{*}{$\begin{array}{l}\text { Weeks of } \\
\text { pupal } \\
\text { collection }\end{array}$} & \multicolumn{5}{|c|}{ Males } & \multicolumn{5}{|c|}{ Females } \\
\hline & \multirow[b]{2}{*}{ No. tested } & \multicolumn{4}{|c|}{ Percentage } & \multirow[b]{2}{*}{ No. tested } & \multicolumn{4}{|c|}{ Percentage } \\
\hline & & $+1+$ & $\mathbf{T}+$ & T1T3 & T3T3 & & $+1+$ & $\mathbf{T}+$ & T1T3 & T3T3 \\
\hline $3-4$ & 38 & 63 & 37 & 0 & 0 & 30 & 33 & 67 & 0 & 0 \\
\hline $5-6$ & 65 & 42 & 58 & 0 & 0 & 4 & 50 & 50 & 0 & 0 \\
\hline $7-8$ & 54 & 32 & 59 & 9 & 0 & 67 & 39 & 61 & 0 & 0 \\
\hline $9-10$ & 37 & 30 & 40 & 30 & 0 & 45 & 30 & 58 & 0 & 12 \\
\hline $11-12$ & 59 & 2 & 38 & 60 & 0 & 43 & 12 & 58 & 0 & 30 \\
\hline $13-14$ & 12 & 8 & 8 & 84 & 0 & 47 & 2 & 79 & 0 & 19 \\
\hline $17-18$ & 6 & 0 & 0 & 100 & 0 & 0 & - & - & - & $\ldots$ \\
\hline
\end{tabular}


fertile progeny. The data in table 3 show that among the males, single heterozygotes became the majority type in the 7th-8th week, but later TIT3 became predominant. Among females T3T3 homozygotes appeared, but translocation heterozygotes remained predominant. No T3T3 males nor T1T3 females were found, indicating that the $\mathrm{Tl}$ and $\mathrm{T} 3$ translocations retained their original linkage to the $M$ and $m$ genes, respectively.

Samples of pupae were taken from the population and the resulting adults were allowed to breed without further T1T3 releases in laboratory cages. Eggs were collected, their hatchability tested and the progeny reared and allowed to breed once more, keeping the successive generations discrete. The results in table 4 show that in each series there was a tendency for a rise in fertility at successive generations, presumably due to selective elimination of the more sterile genotypes. This process of selection was directly detected by outcrossing samples and, in the series started in week 18, the proportion of males scored as T1T3 (less than 40 per cent fertile) declined from 27/28 to $21 / 45$ over four generations of inbreeding (table 4). Among females at the sixth generation there was evidence of an increase in the frequency of wildtype chromosomes at the expense of T3. This was contrary to the prediction of the computer simulation and suggests that some aspect of the fitness of T3T3 is subnormal.

The experiments summarised in table 4 are the approximate equivalent of terminating releases of T1T3 into the main cage population at weeks 13 , 18 and 22, respectively. With a three-fold maximum recovery potential, population recovery of any residual population would have begun when the hatchability exceeded 33 per cent, i.e. after two generations if releases were terminated at week 13, after four generations if releases were terminated at week 18 and not for at least five generations when releases continued until week 22.

\section{(d) DT1T3 male releases}

Seven purified distortion sensitive T3T3 lines were crossed to males of the DTITl stock, eggs were "banked", samples were hatched and males test mated to wild type. These test crosses gave an overall average of 38.7 per cent hatch (from 8662 eggs) and a sex ratio of $1: 13 \cdot 7$ or 6.8 per cent females (from 3800 pupae). Material from all these seven lines was used for the initial releases. One of the T3T3 lines was expanded and used as the female parents of all the DT1T3 males used for the later releases. Test matings with this material showed 37.7 per cent egg hatch and a sex ratio of $1: 17.9$ or $5 \cdot 5$ per cent females.

The DT1T3 releases caused a steady decline in egg hatchability to 30-40 per cent (fig. 3). The proportion of females among the pupae declined sharply to about 25 per cent, where it stabilised for 7 weeks, after which it declined to 5-10 per cent where it remained until the end of the experiment (fig. 3). The course of population suppression resembled that with chemosterilised releases (fig. 4) and releases into the main cage population were terminated in week 13 . In the last stages of the releases, in week 10 , the population had to be collected from the field cage and brought into an indoor cage because cold weather was beginning to prevent regular egg laying. This did not noticeably affect the results, as the marked increase in sex ratio distortion after week 9 was in pupae derived from mating and oviposition which occurred before the move was made. 
C. F. GURTIS $E T A L$.

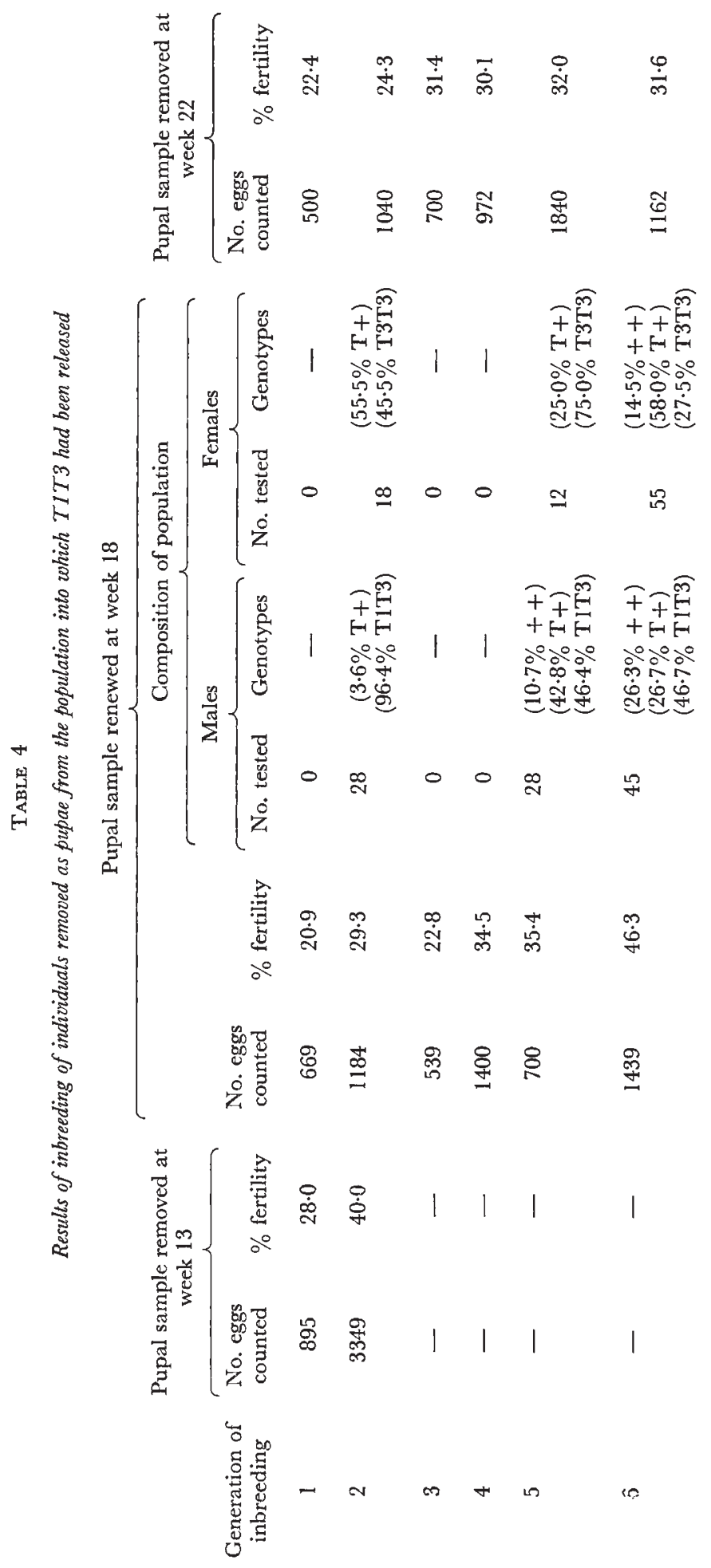


Results of sampling surplus pupae from the population and test mating the resulting adults are shown in table 5. The test matings of males (which were made to an $m^{d} m^{d}$ stock) showed the rapid appearance of a high frequency of the distorter type. From half of the samples, the progeny of non-distorter males was tested to determine the cause of non-distortion. These tests indicated that both the non-distorter $M$ allele, $M^{d}$, and the distortion resistant $m, m^{D}$, were present at low frequency in the final week of releases. The high ratio of distorters $\left(M^{D} m^{d}\right)$ to $M^{D} m^{D}$ at that time (table 5) indicated that the

TABLE 5

Results of test crosses of individuals sampled as pupae from the population exposed to DTIT3 releases

\begin{tabular}{|c|c|c|c|c|c|c|c|c|c|c|}
\hline \multirow{4}{*}{$\begin{array}{c}\text { Weeks of } \\
\text { pupal } \\
\text { collection }\end{array}$} & \multicolumn{6}{|c|}{ Males } & \multicolumn{4}{|c|}{ Females } \\
\hline & & & \multicolumn{4}{|c|}{ Percentage } & \multicolumn{4}{|c|}{ Percentage } \\
\hline & \multirow{2}{*}{$\begin{array}{l}\text { No. } \\
\text { tested }\end{array}$} & \multirow{2}{*}{$\begin{array}{l}\text { Mean } \% \\
\text { fertility }\end{array}$} & \multirow{2}{*}{$\begin{array}{l}\text { Distorter } \\
\left(M^{D} m^{d}\right)\end{array}$} & \multicolumn{3}{|c|}{ Non-distorter } & \multirow{2}{*}{$\begin{array}{l}\text { No. } \\
\text { tested }\end{array}$} & & \multicolumn{2}{|c|}{ Homozygotes } \\
\hline & & & & $M^{D} m$ & & $M^{d} m^{-}$ & & $\mathrm{T}+$ & ++ & T3Т3 \\
\hline $1-2$ & 15 & $75 \cdot 1$ & 80 & - & $20^{*}$ & 一 & 0 & - & - & - \\
\hline $3-4$ & 42 & 79.0 & 83 & 3 & & 14 & 0 & - & - & - \\
\hline $5-6$ & 0 & - & - & - & & - & 71 & 76 & & \\
\hline $7-8$ & 18 & $74 \cdot 7$ & 67 & & $33 *$ & & 86 & 58 & & \\
\hline $9-10$ & 24 & $74 \cdot 5$ & 67 & & $33^{*}$ & & 41 & 58 & & \\
\hline $11-12$ & 10 & $93 \cdot 4$ & 70 & 20 & & 10 & 0 & - & & \\
\hline $13-14$ & 107 & $78 \cdot 2$ & 89 & 5 & & 6 & 18 & 27 & 39 & 33 \\
\hline
\end{tabular}

* $\mathrm{F}_{1}$ not tested and complete classification of these individuals was therefore not possible.

release of large numbers of males carrying $m^{d}$ had considerably reduced the $m^{D}$ frequency in the cage population below the 30 per cent level in the initial population. There was an unexpectedly high average fertility among males from the cage population when outcrossed (table 5). No attempt was made to classify the individual genotypes because of the known high and variable fertility of the DT1 + type (fig. 1). Among the females, T3T3 homozygotes, single heterozygotes and wild types were all present in weeks 13-14 at approximately equal frequency.

As with the other two types of release material, the observed and expected ratios of marked:unmarked males generally corresponded (table 2), indicating approximately normal survival of DT1T3 males.

The data in fig. 4 refers to the main cage population into which DTIT3 releases were continued until the time of eradication. To test the effect of an earlier termination of releases, surplus pupae from the cage population were inbred in laboratory cages without DTIT3 releases, but using the same system of population management, giving overlapping generations, as in the main cage. The numbers of pupae introduced were initially the same as the calculated input for the main cage but, when eggs and pupae were produced by the new population, their hatchability and sex ratio were used to calculate the numbers to be re-cycled. Results are shown in table 6 . In both populations the fertility rose, presumably due to selective elimination of the more sterile translocation genotypes. In the population separated at week 9 there was a weak but stable level of sex ratio distortion inherited for 14 weeks. The combined effect of the inherited sterility and distortion in this population 
was insufficient to complete the process of eradication, and a trend towards population recovery was apparent after week 22 .

The population separated in week 11 initially showed high sterility with strong sex ratio distortion and, within 4 weeks, the calculated number of female pupae for input into the cage declined to zero. Thus it is concluded that 11 weeks of DT1T3 releases were sufficient to achieve eradication under the conditions specified. Surplus eggs were still available from this population at week 15, and 40 females and 200 males from these were mated and a

TABle 6

Results of inbreeding individuals samples as pupae from the population which had been exposed to DT1T3 releases

\begin{tabular}{|c|c|c|c|c|c|c|}
\hline \multirow[b]{2}{*}{ Week } & \multicolumn{3}{|c|}{ Population sample from week 9} & \multicolumn{3}{|c|}{ Population sample from week 11} \\
\hline & $\begin{array}{c}\% \text { egg } \\
\text { hatchability }\end{array}$ & $\begin{array}{c}\% \text { female } \\
\text { pupae }\end{array}$ & $\begin{array}{l}\text { Input of females } \\
\text { into population* }\end{array}$ & $\begin{array}{c}\% \text { egg } \\
\text { hatchability }\end{array}$ & $\begin{array}{l}\% \text { female } \\
\text { pupae }\end{array}$ & $\begin{array}{l}\text { Input of fem } \\
\text { into populat }\end{array}$ \\
\hline 10 & $55 \cdot 8$ & - & $13 \cdot 6$ & - & - & - \\
\hline 11 & $53 \cdot 9$ & $25 \cdot 8$ & $4 \cdot 7$ & - & - & - \\
\hline 12 & $54 \cdot 8$ & $34 \cdot 8$ & $13 \cdot 0$ & $43 \cdot 1$ & - & $2 \cdot 2$ \\
\hline 13 & $65 \cdot 8$ & $30 \cdot 5$ & $7 \cdot 3$ & $38 \cdot 6$ & - & 0.3 \\
\hline 14 & $58 \cdot 2$ & $25 \cdot 1$ & $12 \cdot 2$ & $25 \cdot 4$ & $20 \cdot 4$ & 0.3 \\
\hline \multirow[t]{2}{*}{15} & $62 \cdot 8$ & $29 \cdot 6$ & $6 \cdot 3$ & $22 \cdot 6$ & $3 \cdot 6$ & 0 \\
\hline & & & & \multicolumn{3}{|c|}{ Progeny of all remaining eggs mated } \\
\hline 16 & $66 \cdot 5$ & $30 \cdot 4$ & $9 \cdot 5$ & $79 \cdot 1$ & - & - \\
\hline 17 & $73 \cdot 7$ & $26 \cdot 8$ & $7 \cdot 9$ & $69 \cdot 7$ & $15 \cdot 2$ & - \\
\hline 18 & 68.7 & $26 \cdot 9$ & $9 \cdot 2$ & $68 \cdot 1$ & $16 \cdot 3$ & - \\
\hline 19 & $69 \cdot 6$ & $23 \cdot 7$ & $9 \cdot 8$ & 63.5 & $21 \cdot 8$ & - \\
\hline 20 & 71.8 & $23 \cdot 3$ & $6 \cdot 3$ & $63 \cdot 1$ & 13.9 & - \\
\hline 21 & $72 \cdot 2$ & $31 \cdot 1$ & $13 \cdot 0$ & $62 \cdot 6$ & $18 \cdot 2$ & - \\
\hline 22 & $74 \cdot 6$ & $29 \cdot 7$ & $6 \cdot 7$ & $65 \cdot 8$ & $25 \cdot 0$ & - \\
\hline 23 & $72 \cdot 1$ & $33 \cdot 4$ & 14.9 & $72 \cdot 8$ & $29 \cdot 4$ & - \\
\hline 24 & $79 \cdot 8$ & 30.4 & $13 \cdot 6$ & $76 \cdot 6$ & $24 \cdot 6$ & - \\
\hline 25 & $86 \cdot 6$ & $28 \cdot 6$ & $18 \cdot 1$ & $74 \cdot 7$ & $21 \cdot 3$ & $\ldots$ \\
\hline 26 & $75 \cdot 4$ & $33 \cdot 5$ & $21 \cdot 5$ & $75 \cdot 9$ & $26 \cdot 2$ & - \\
\hline
\end{tabular}

cycling population was continued for them with a standard input of all the pupae derived from 200 first instar larvae cultured each day. The fertility increased markedly and the strength of sex ratio distortion gradually declined.

To investigate the causes of the decline in strength of sex ratio distortion in the two cage populations referred to in table 6, male pupae were sampled at weeks 21-22, and, after eclosion, males were mated to $m^{d} m^{d}$ females. The number of distorter males was recorded and the sons of each non-distorter were test mated to distinguish $M^{D} m^{D}$ parents from $M^{d} m^{-}$parents. The results, compared with pooled data from table 5 for the samples taken in weeks 11-14 (while DT1T3 releases were still going on and distortion was very strong), were as follows:

\begin{tabular}{cccc} 
& \multicolumn{3}{c}{$\mathcal{N}$. of males identified } \\
& $M^{D} m^{d}$ & $M^{D} m^{D}$ & $M^{d_{m}}$ \\
weeks 11-14 & 102 & 7 & 8 \\
weeks 21-22 & 141 & 32 & 9
\end{tabular}


Comparison of the frequency of $M^{D} m^{D}$ with $M^{D} m^{d}$ in the two sets of data indicated a significant rise in $m^{D}$ frequency over the approximately 10 -week period $\left(\chi^{2}=8.23, \mathrm{P}<0.01\right)$. Such a rise is to be expected in a population breeding without releases and containing the $M^{D}$ gene and was predicted by the computer simulations.

The effect of the genetic load of translocations and meiotic drive combined with a three-fold recovery potential may be assessed as follows:

$$
\text { Egg hatchability } * \times \frac{\text { proportion of female pupae } \times 3}{0.5}
$$

If this quantity exceeds 1.0 it indicates that population increase would occur. The data indicate that for several weeks a residual population of the observed composition would have continued to decline, but by week 24 a slow recovery would have begun.

\section{Discussion}

The present study has shown the feasibility of preparing and releasing on a regular daily basis moderate numbers of chemosterilised, double translocation heterozygote and distorter double translocation heterozygote males of $A$. aegypti. The experiment has also confirmed that males of each type survived and competed for mating and therefore were able to introduce very large genetic loads into cycling populations of wild origin. In populations with a three-fold maximum recovery potential, the genetic loads from all three systems were sufficient to cause eradication.

The T1T3 and chemosterilised experiments were started at the same time and therefore are fully comparable. The DT1T3 experiment had to be conducted in a cooler season, but it seems unlikely that this factor significantly affected the validity of the comparison of it with the other systems.

In terms of both duration of releases required to achieve eradication and rate of population suppression, the TIT3 system was less efficient than the other two systems. Where releases of T1T3 were terminated after 13 weeks, only about 80 per cent population suppression had been reached (fig. 4) and recovery began after about two generations (table 4). By releasing for 18 or 22 weeks, however, greater suppression and more prolonged control of the residual population was achieved (table 4 ) and 23 weeks of releases suppressed the population to the point of eradication. (fig. 4).

With chemosterilised and DT1T3 releases, considerably shorter release schedules were needed for eradication (fig. 4). With chemosterilised males it was considered necessary to continue releases to week 12 , so as to ensure that a large number of sterile males were present when the last females in the population mated. Releases of DT1T3 for 11 weeks was sufficient to suppress the population to a very low level and to leave in it so much inherited genetic load that eradication of the remainder occurred (table 6).

The first isolate of DT1T3 which was described by Suguna and Curtis (1974) had relatively weak sex ratio distortion and it seemed at that time that $\mathrm{DTl}+$ single heterozygotes, because of their stronger distortion, might be superior to DTIT3 for genetic control purposes. However, as reported in

* No correction is made here for the 1-7 per cent of natural sterility, because this correction was omitted from the routine calculations of pupal input. 
this paper, T3T3 lines which yield DTIT3 with strong distortion have now been produced. Therefore, work with DTl + was not pursued, because of its much lower sterility level compared with DTIT3.

There was a satisfactory resemblance between the results obtained (fig. 4) and the computer predictions (fig. 2), but none of the systems behaved quite as well as predicted, i.e. in no case was 8-9 weeks of release sufficient to achieve the conditions necessary for eradication, perhaps because of slightly reduced competitiveness in the released males.

As indicated the computer model used was only an approximation to the true complexity of the population genetics of the T1T3 and DT1T3 systems. It will have to be modified to predict reliably the long-term consequences of releases and to study to what extent residual populations left after DT1T3 or TIT3 releases would be able to control re-establishment of epidemiologically significant populations deriving from immigrants, "pockets" which were not adequately covered by a release programme, or the hatching of hitherto dormant eggs. If residual populations, genetically loaded with translocations and/or sex ratio distortion, could delay the need to re-start releases to deal with such problems, this would be a valuable feature of the inherited systems. However, it is clear that if the release programme had been successful in greatly reducing population density, the influx of more than a very few wild type individuals would "dilute" the genetic load with a large proportion of normal chromosomes.

Acknowledgments.-We are grateful to the staff of the Aedes Genetics and Induced Sterility Iaboratories of the Unit for their conscientious technical assistance, to $\mathrm{Mr} \mathrm{A}$. Thomas for computer programming and to the Mass Rearing Laboratory of this Unit for the supply of pupae for sterilisation.

We thank Dr A. B. Borkovec for the supply of thiotepa, Drs K. S. Rai and N. Lorimer for the supply of the T1 and T3 translocations and Dr R. J. Wood for the supply of a stock carrying the sex ratio distorter gene.

We are grateful to Dr G. D. Brooks for his support and encouragement and for his comments on the manuscript.

\section{REFERENCES}

CRAIG, G. B., AND HICKEY, w. A. 1967. Genetics of Aedes aegypti. In Genetics of Insect Vectors of Disease, ed. J. W. Wright and R. PaI, pp. 67-128. Elsevier, Amsterdam.

CURTIS, C. F., LORIMER, N., RAI, K. s., SUGUNA, S. G., UPPAL, D. K., KAZMI, s. J., hallinAN, E., AND DIETZ, K. 1975. Simulation of alternative genetic control systems for Aedes aegypti in outdoor cages and with a computer. WHO/VBC 75.516 (unpublished WHO document).

CURTIS, C. F., AND RoBinson, A. s. 1971. Computer simulation of the use of double translocations for pest control. Genetics, 69, 92-113.

FAY, R. W. 1964. The biology and bionomics of Aedes aegypti in the laboratory. Mosq. Neres, 24, 300-308.

FAY, R. W., AND ELLIASON, D. A. 1966. A preferred oviposition site as a surveillance method for Aedes aegypti. Mosq. News, 26, 531-535.

GROVER, K. K., AND AGARWAL, H. v. 1975. Studies on the chemosterilization of Aedes aegypti. 1. Evaluation of thiotepa as a sterilant in laboratory and field cages. WHO/VBC 75.558 (unpublished WHO document).

GROVER, K. K., AND SHARMA, v. P. 1974. The present status of the work on induced sterility mechanisms for control of mosquitos Culex pipiens fatigans and Aedes aegypti at the WHO/ ICMR Research Unit on Genetic Control of Mosquitos. 7. Com. Dis., 6, 91-97.

HICKEY, w. A. I970. Factors influencing distortion of sex ratio in Aedes aegypti. 7 . med. Entomol., 7, 727-735. 
HICKEY, W. A., AND CRAIG, G. B. 1966a. Distortion of sex ratio in populations of Aedes aegypti. Can. 7. Genet. and Cytol., 8, 260-278.

Hickey, W. A., AND CRAIG, G. B. 1966b. Genetic distortion of sex ratio in the mosquito Aedes aegypti. Genetics, 53, 1177-1196.

LORIMER, N., HALlinAN, E., AND RAI, K. s. 1972. Translocation homozygotes in the yellow fever mosquitos, Aedes aegypti. 7. Hered., 63, 159-166.

MCDONALD, P. T., AND RAI, K. s. 1971. Population control potential of heterozygous translocations as determined by computer simulations. Bull. Wld. Hlth. Org., 44, 829-845.

RAI, K. S., LORIMER, N., AND HALlinan, E. 1974. The present status of genetic methods for controlling Aedes aegypti. In The Use of Genetics in Insect Control, ed. R. Pal and M. Whitten pp. 119-132. Elsevier, Amsterdam.

REUben, R., PANIGKeR, K., DAS, P. K., KAzMI, s. J., AND sugunA, s. G. 1975. A new paddle for the black jar ovitrap for surveillance of Aedes aegypti. WHO/VBC 75.548 (unpublished WHO document).

SINGH, K. R. P., BROOKs, G. D., AND ANSARI, M. A. 1974. Mass rearing of mosquitos. J. Com. Dis., 6, 121-126.

SiNGH, K. R. P., RAZDAN, R. K., VAIDYANATHAN, v., AND MAlHotrA, P. R. 1975. Caging, marking and transportation of Culex pipiens fatigans for large scale genetic control operations. WHO/VBC 75.524 (unpublished WHO document).

suguna, s. G., AND curtis, c. F. 1974. Sex ratio distorter strains in Aedes aegypti. F. Com. Dis., 6, 102-105.

SUgunA, S. G., KAZMI, s. J., AND GURTIS, C. F. 1975. Sex ratio distorter translocation homozygotes in Aedes aegypti. WHO/VBC 75.542 (unpublished WHO document).

UPPAL, D. K., CURTIS, C. F., AND RAI, K. s. 1974. A double translocation heterozygote in Aedes aegypti. 7. Com. Dis., 6, 98-101.

whrte, G. B. 1966. Chemosterilization of Aedes aegypti by pupal treatment. Nature, 210, 1372-1373. 